\title{
Jungpaläozoische Glazialspuren auf dem Arabischen Schild
}

\author{
Vorläufige Mitteilung \\ Von Ahmed H. HeLal, Ryad
}

Ausgedehnte geologische Kartierungen des Ministry of Agriculture von Saûdi Arabien werden zur Zeit westlich des Rub al-Khali an den Südausläufern des Dj. Tuwaik zur Wassererschließung durchgeführt.

Detailliertere Profilstudien im Gebiet zwischen $18^{\circ}-19^{\circ}$ nördl. Br. und $44^{\circ} 30^{\prime}-46^{\circ}$ östl. v. Greenwich (vgl. Abb. 1) ergeben östlich des Dünenfeldes von N ef u d E d D a h i an den Westabstürzen des Dj. Tuwaik folgendes allgemeine und regional weitverbreitete Profilbild:

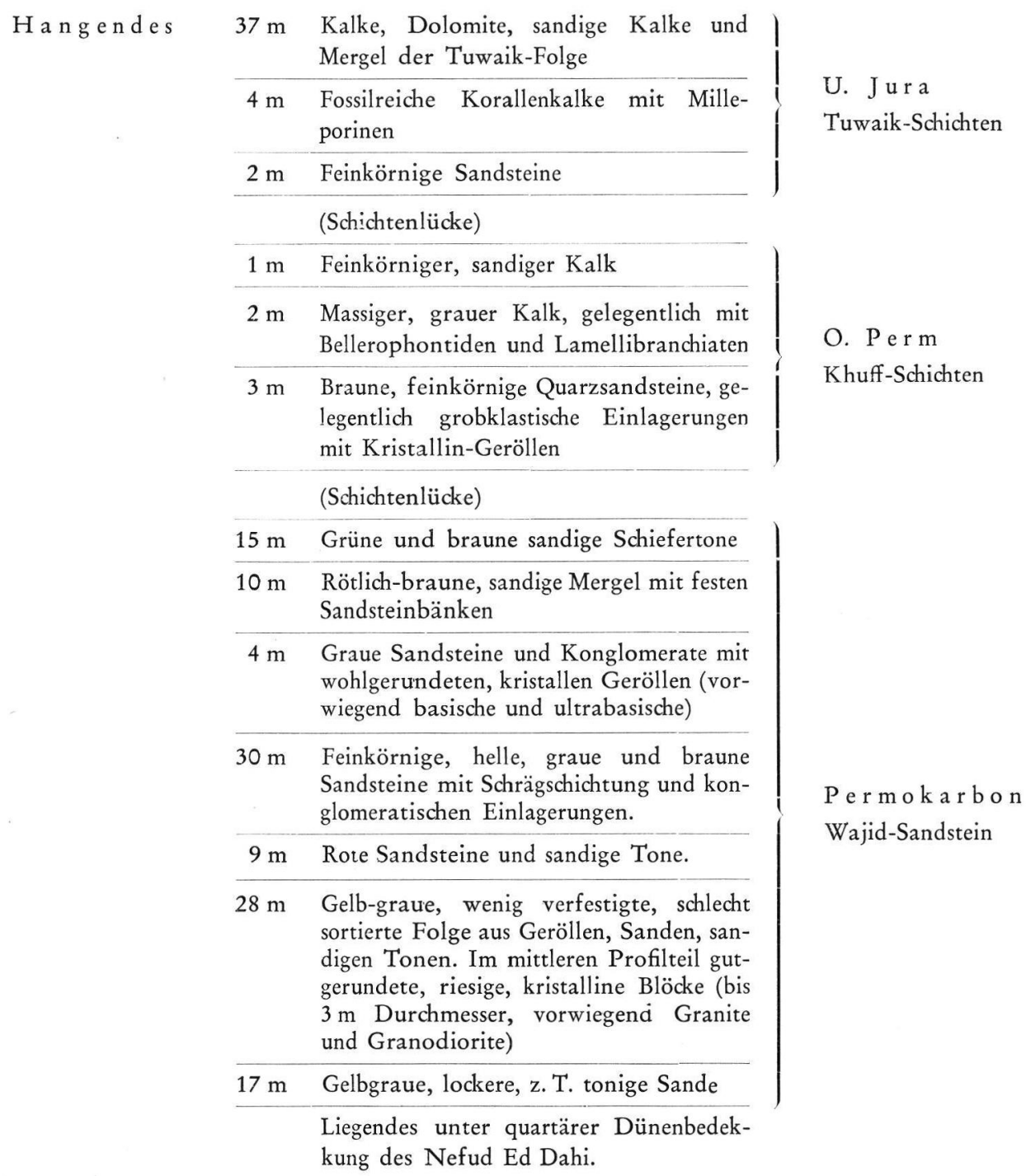




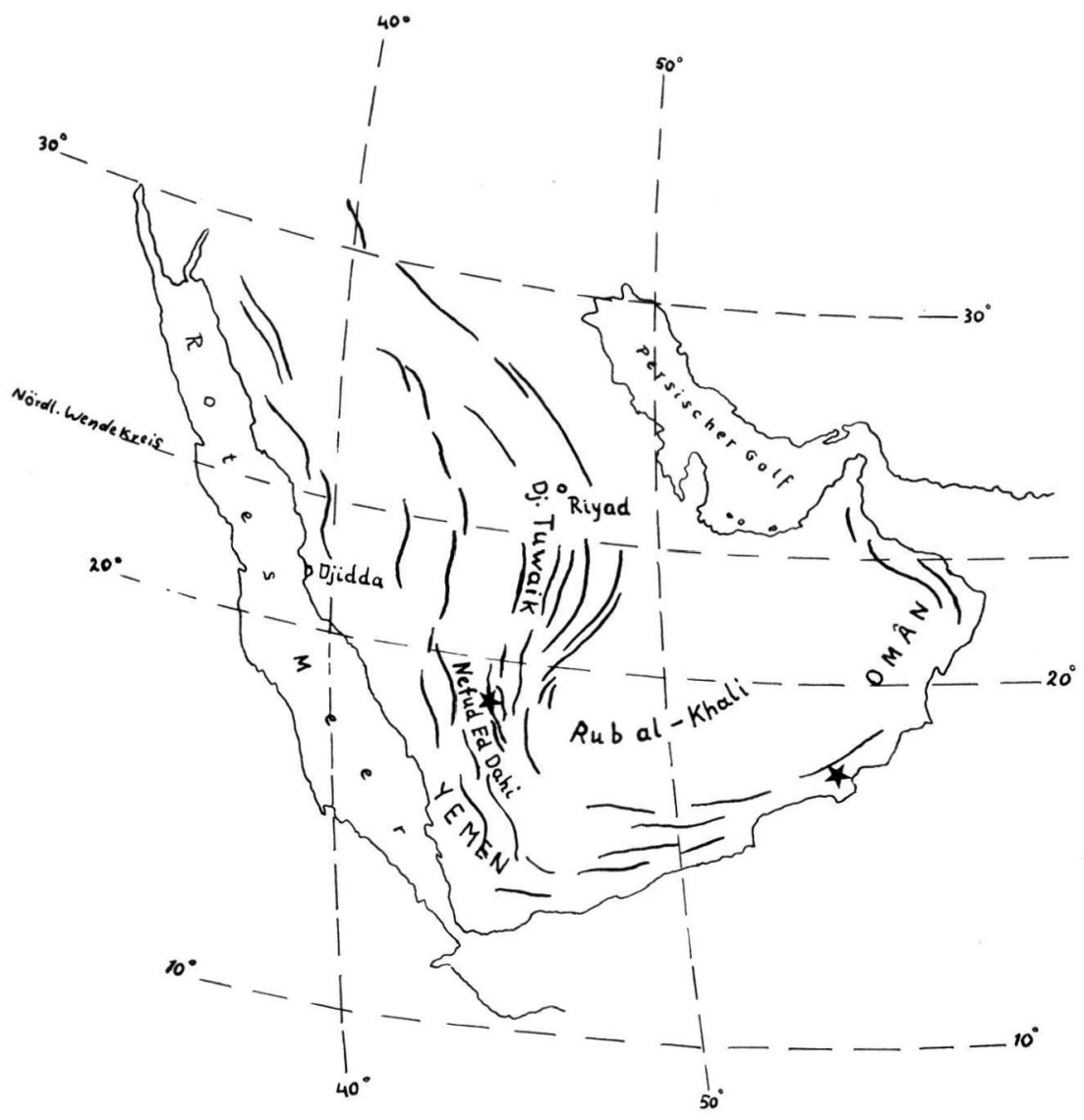

Abb. 1. Vorkommen von Glazialspuren in Arabien. $*=$ Tillit-Funde.

Im Wajid-Sandstein konnten in diesem Gebiet noch keine Fossilien beobachtet werden. Man findet aber in diesem Schichtenstapel weiter nördlich fossile Hölzer, die auf ein permokarbonisches Alter hinweisen. Noch ältere, paläontologisch zu datierende Ablagerungen sind im weiteren Bereich nicht bekannt; stattdessen tritt das Grundgebirge des Arabischen Schildes ungefähr $100 \mathrm{~km}$ weiter westlich allgemein zutage (Granite, Syenite, Gneise etc.).

Wegen der teilweise gewaltigen Größe ortsfremder und zudem geschrammter Blöcke, ihrer unsortierten Einlagerung im Schichtenverband, ihrer weiten Verbreitung und Verzahnung mit offensichtlich fluviatilen Ablagerungen läßt sich der Schluß ziehen, daß es sich mindestens bei der unteren „Konglomeratlage“ um permoka rbonische Til1 i t e handelt. Der Transportweg darf mit gutem Grund als von Westen nach Osten verlaufend angenommen werden.

Es ist dies der zweite Hinweis für jungpaläozoische Vereisungsspuren in Arabien, nachdem erst vor einigen Jahren Hudson (vgl. in Scrwarzbach, 1961 und KING, 1958) ähnlich ausgebildete Profile mit Tilliten aus dem südwestlichen Oman (Abb. 1) angegeben hat. Jedoch sind die vom Dj. Tuwaik genannten Vorkommen an die $1000 \mathrm{~km}$ weiter westlich gelegen.

Beide arabische Vorkommen liegen in ähnlichem stratigraphischen Niveau und schließen an die bekannten und viel diskutierten, indischen Vorkommen an (vgl. S 1961). 


$$
\text { Angef ̈̈hrte } \mathrm{Schriften}
$$

KING, L. C.: Basic palaeogeography of Gondwanaland during the late Palaeozoic and Mesozoic eras. - Q. J. G. S., 114, London 1958.

SchwarzBach, M.: Das Klima der Vorzeit. - 2. Aufl., Stuttgart 1961.

Manuskr. eingeg. 29. 3. 1963.

Anschrift des Verf.: Dr. Ahmed H. Helal, King-Saud-University, Geol. Dept., Fac. of Science, Ryad, Saûdi Arabien. 